\title{
Feasibility study of the minimum quantity lubrication in high-speed end milling of NAK 80 hardened steel by coated carbide tool
}

\author{
Y.S. Liao ${ }^{\mathrm{a}, *}$, H.M. Lin ${ }^{\mathrm{a}}$, Y.C. Chen ${ }^{\mathrm{b}}$ \\ ${ }^{a}$ Department of Mechanical Engineering, National Taiwan University, Taipei 106, Taiwan \\ ${ }^{\mathrm{b}}$ Mechanical and Systems Research Laboratories (MSL)/Industrial Technology Research Institute (ITRI), Taiwan
}

Received 24 October 2006; received in revised form 6 January 2007; accepted 13 January 2007

Available online 4 February 2007

\begin{abstract}
High-speed milling of hardened steels generates high cutting temperature and leads to detrimental effects on tool life and workpiece surface finish. In this paper, feasibility study of the minimum quantity lubrication (MQL) in high-speed end milling of NAK80 hardened steel by coated carbide tool was undertaken. Flood cooling and dry cutting experiments were conducted also for comparison. It is found that cutting under flood cooling condition results in the shortest tool life due to severe thermal cracks while the use of MQL leads to the best performance. MQL is beneficial to tool life both in the lower speed cutting and the higher speed cutting conditions. A less viscous oil of MQL is essential in high cutting speed so that cooling effect can be effective. SEM micrograph of the insert shows that the use of MQL in high-speed cutting can delay welding of chips on the tool and hence prolongs tool life as compared with dry cutting condition. The application of MQL also improves machined surface finish in high-speed milling of die steels.
\end{abstract}

(C) 2007 Elsevier Ltd. All rights reserved.

Keywords: High-speed milling; Hardened steels; Tool life; Minimum quantity lubrication

\section{Introduction}

High-speed milling (HSM) of hardened steels, which resulted from the advancement of the machine tools, new cutting tool materials and the coating techniques, is now recognized as an alternative of the conventional die and mold making process. Comparing with the conventional methods, HSM has the advantage of reducing lead times and machining cost. But tool life is greatly shortened and machined surface finish is deteriorated due to rapid wear rate of the cutting tool caused by the high cutting temperature resulting from high cutting speed. CBN tools have successfully been used in HSM of hardened tool steels due to their high degree of hot hardness [1,2]. But despite their superior tool life, the cost of CBN cutting tools restricts their widespread use in industry. $\mathrm{Al}_{2} \mathrm{O}_{3}$ can be used in HSM of steels; however, it is very brittle. Cemented carbide is the most commonly used cutting tool for the machining of steels. In order to improve the machinability

\footnotetext{
${ }^{*}$ Corresponding author. Tel.: + 886223626431 ; fax: + 886223631755

E-mail address: liaoys@ntu.edu.tw (Y.S. Liao).
}

of carbide tools in the HSM of hardened steels, they are usually coated with single or multi-layers of TiN, TiCN, and TiAlN coatings by chemical vapor deposition (CVD) or physical vapor deposition (PVD) techniques [1-4]. The investigations into HSM of hardened steels with coated carbide end mills revealed that the tool life of the TiAlNcoated tool was superior to those observed on the tool with TiCN coating or $\mathrm{TiCN}+\mathrm{Al}_{2} \mathrm{O}_{3}+\mathrm{TiN}$ multi-layer coating. However, the high temperature during HSM is still a problem remaining to be solved. The flood type cutting fluid is usually adopted to reduce cutting temperature, lubricate the sliding surface during machining [5]. Nevertheless, it should be noted that the application of copious amount of fluid during intermittent cutting could increase a large fluctuation of cutting temperature. This in turn leads to thermal shock and could initiate thermal cracks of the cutting edge and eventually tool failure due to edge fracture [6-8]. Besides, there are problems of environmental pollutions and waste disposals in the usage of flood coolant. In order to alleviate the above-mentioned negative effects, the idea of semi-dry or near-dry machining, the socalled minimum quantity lubrication (MQL) which uses a 
very small amount of oil mixed with copious amount of high pressure air in machining, has been proposed.

There have been many studies of MQL machining in the past. It was revealed that MQL could be widely utilized in the machining of aluminum and aluminum alloys [9-12]. With respect to steels, the researches and applications of MQL are mainly focused on the drilling and turning operations [10,13-18]. The investigations of milling process with MQL [19,20], especially in high-speed cutting of hardened steel are still immature and the related researches remain open. Regarding the milling of hardened steel, experiments were conducted on the ASSAB 718HH steel of $35 \mathrm{HRc}$ with the use of uncoated carbide tool and high viscous lubricating oil $\left(29\right.$ centistoke $(\mathrm{cSt})$ at $\left.40^{\circ} \mathrm{C}\right)$ to evaluate the performance of MQL by Rahman et al. [20]. It was found that there was a considerable reduction in cutting force for MQL as compared with dry cutting and flood cooling conditions, especially at low cutting speed (such as $75 \mathrm{~m} / \mathrm{min}$ ). The results demonstrated that MQL might be regarded as an economical and environmentally compatible lubrication technique for low speed, feed rate, and depth of cut condition. On the contrary, MQL seemed to have no effect on the improvement of tool performance in high-speed milling such as $125 \mathrm{~m} / \mathrm{min}$.

The objective of the present work is to study if the application of MQL could be utilized effectively in highspeed end milling of hardened die steel with the use of coated carbide tool. The viscosity of oils for MQL is taken into account as well. Tool life and machined surface roughness under various cutting conditions including dry, flood cooling, and MQL are evaluated. SEM micrograph and EDAX analysis are used to investigate the cutting behaviors of MQL.

\section{Experiment}

The experiments were conducted on a vertical high-speed machining center (Vector65/I). The work material was NAK80 die steel (similar to AISI P21, 41HRc) with the chemical composition of $0.15 \% \mathrm{C}, 0.30 \% \mathrm{Si}, 3.0 \% \mathrm{Ni}$, $1.5 \% \mathrm{Mn}, 0.30 \% \mathrm{Mo}, 1.0 \% \mathrm{Al}$, and $1.0 \% \mathrm{Cu}$, and it was prepared in $100 \mathrm{~mm} \times 100 \mathrm{~mm} \times 80 \mathrm{~mm}$ block. End milling experiments under dry cutting, flood coolant, and MQL conditions were conducted. The Castrol Superedge B7 water-soluble coolant in a flow rate of $1,200,000 \mathrm{ml} / \mathrm{h}$
$(20,000 \mathrm{ml} / \mathrm{min})$ was used as the flood coolant, and the less viscous Castrol Carecut ES3 $\left(5 \mathrm{cSt}\right.$ at $\left.40^{\circ} \mathrm{C}\right)$ was adopted as MQL oil. The MQL oil mist was supplied with a Steidle micro lubricating system (Lubrimat L50) in a very small amount of flow rate $(10 \mathrm{ml} / \mathrm{h})$ at a pressure of $0.45 \mathrm{MPa}$.

The Sandvik indexable carbide insert (R390-11T308MPM 1025) coated with TiAlN and TiN, which could provide higher heat resistance, was mounted on a $16 \mathrm{~mm}$ diameter end mill with an inclination angle of $8^{\circ}$ and a top rake angle of $20^{\circ}$. The cutting speed, $V$, was set at 150,200 , and $250 \mathrm{~m} / \mathrm{min}$. The feed rate, fz, was set at $0.10,0.15$, and $0.20 \mathrm{~mm} /$ tooth. The axial depth of cut and the radial depth of cut were 0.6 and $5 \mathrm{~mm}$, respectively. Tool wear was measured by a Nikon toolmaker's microscope (Type MM40) once every certain passes of milling depending on the tool wear rate and was examined by the use of SEM (JEOL-6360LV). Tool life in terms of the total cutting length was recorded after a tool life criterion of $0.1 \mathrm{~mm}$ maximum flank wear/groove wear has reached [7,21]. In the paper, this is defined as the end of cutting. The cutting force was measured and recorded through a Kistler type 9257BA dynamometer, a charge amplifier (Type 5233A), and a PC software. Workpiece surface roughness, $R_{\mathrm{a}}$, was measured via a Taylor-Hobson instrument (Type Surtronic $3+$ ), with cutoff and evaluation length set at 0.8 and $4 \mathrm{~mm}$, respectively. All measurements were repeated three times, and the average of these three measurements was taken as the final value of tool wear, surface roughness, and cutting force.

\section{Results and discussions}

\subsection{Tool life}

Analyses of variance (ANOVA) for evaluating the significance level of cutting speed, feed rate, and lubricating method on tool life and resultant cutting force are given in Tables 1 and 2, respectively. The criterion for a confidence level of $95 \%$, or $P$-value less than 0.05 , is used to determine which factor is significant. It is revealed from Table 1 that all the three factors have significant influences on tool life (in the paper, it is represented by cutting length). However, the cutting force as shown in Table 2 is affected apparently by the feed rate and lubricating method, while the cutting speed is an insignificant factor. This is due to the fact that

Table 1

Analysis of variance (ANOVA) for tool life (cutting length)

\begin{tabular}{|c|c|c|c|c|c|}
\hline Source & Sum of squares & d.f. & Mean square & $F$ & $P$-value \\
\hline Feed rate & 161.79 & 2 & 80.90 & 7.69 & 0.0033 significant \\
\hline Cutting environment & 323.53 & 2 & 161.76 & 15.37 & $<0.0001$ significant \\
\hline Residual & 210.49 & 20 & 10.52 & & \\
\hline Total (corrected) & 1862.56 & 26 & & & \\
\hline
\end{tabular}


Table 2

Analysis of variance (ANOVA) for resultant cutting force

\begin{tabular}{|c|c|c|c|c|c|}
\hline Source & Sum of squares & d.f. & Mean square & $F$ & $P$-value \\
\hline Model & 5690.41 & 6 & 948.40 & 71.49 & $<0.0001$ significant \\
\hline Feed rate & 5359.42 & 2 & 2679.71 & 201.99 & $<0.0001$ significant \\
\hline Cutting speed & 9.18 & 2 & 4.59 & 0.35 & 0.7118 \\
\hline Cutting environment & 321.82 & 2 & 160.91 & 12.13 & 0.0004 significant \\
\hline Residual & 265.34 & 20 & 13.27 & & \\
\hline Total (corrected) & 5955.75 & 26 & & & \\
\hline
\end{tabular}

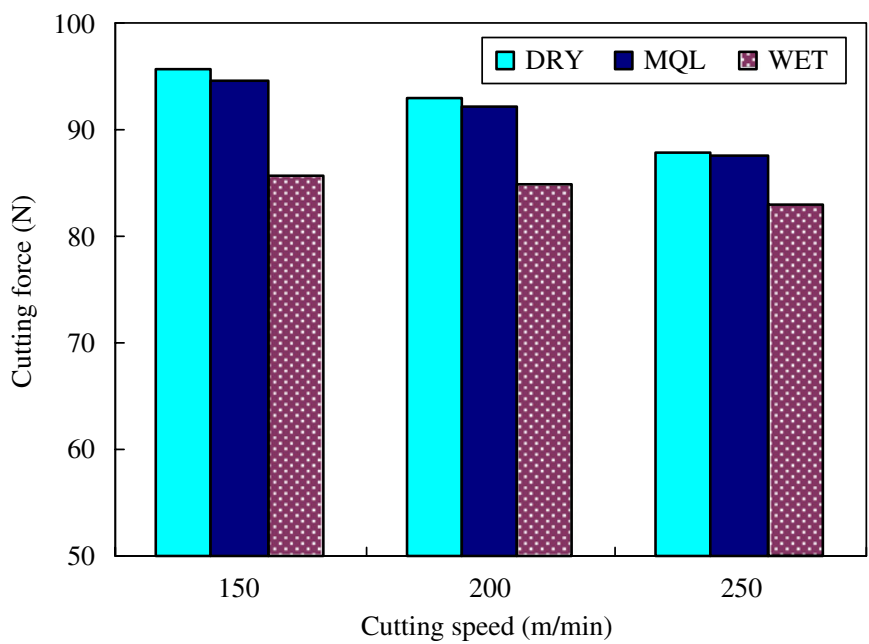

Fig. 1. Average resultant cutting force as a function of cutting speed and lubricating method at feed rate of $0.15 \mathrm{~mm} /$ tooth.

the cutting force is strongly correlated with the chip thickness, which is associated with the feed rate. In addition, the application of lubricants is believed to reduce the friction coefficient between the chip-tool interfaces. On the contrary, the cutting force would only decrease slightly with the increase of cutting speed, as general expectation.

Fig. 1 shows the cutting force as a function of cutting speed under various lubricating methods. All of the three cutting force components vs. cutting speed have similar declining trend under dry, MQL, and flood cooling cutting conditions. The forces from the least to the largest are in the order of flood cooling, MQL, and dry cutting conditions for all three cutting speeds. Fig. 2 shows the tool life with respect to feed rate and lubricating methods at the cutting speeds of 150,200 , and $250 \mathrm{~m} / \mathrm{min}$. As aforementioned, the cutting force in flood cooling (wet) is lower than those under dry cutting and MQL conditions; whereas the lines shown in Fig. 2 depict that tool life is in the increasing order of flood cooling, dry cutting, and MQL condition for all three cutting speeds. The reason of very unsatisfactory tool life under flood cooling condition is due to the occurrence of thermal cracks on the cutting edge caused by thermal shock. This in turn results from severe heat variation during high-speed intermittent cutting. The cutting tool in flood cooling under the cutting condition of $V=250 \mathrm{~m} / \mathrm{min}, \mathrm{fz}=0.15 \mathrm{~mm} /$ tooth is shown in Fig. 3. It can be seen from Fig. 3(a) that there are many large thermal cracks on the cutting edge after $1.8 \mathrm{~m}$ cutting length. The large thermal cracks resulted from a large variation of cutting temperature. They reduce the strength of the cutting edge rapidly and cause catastrophic fracture of the cutting edge after $1.9 \mathrm{~m}$ cutting length as that displayed in Fig. 3(b). The SEM micrographs of cutting tool under flood cooling condition at the cutting speed of $V=150 \mathrm{~m} / \mathrm{min}$ when $0.1 \mathrm{~mm}$ maximum flank wear/groove wear has reached is given in Fig. 4(a), and that observed when the rake face is oriented $-45^{\circ}$ with respect to the cutting edge is given in Fig. 4(b). The similar SEM micrographs under the cutting speed of $V=200 \mathrm{~m} / \mathrm{min}$ are given in Fig. 4(c) and (d), respectively. There are more intensive thermal cracks in Fig. 4(c) and (d) than those in Fig. 4(a) and (b). This indicates that more severe thermal shock would be induced when the cutting speed is increased, and the tool life becomes shorter as a result. Hence, flood cooling is believed unsuitable for high-speed milling of hardened die steel.

It was reported by Rahman et al. [20] that MQL was effective especially at low cutting speed (for example $75 \mathrm{~m} / \mathrm{min}$ ), but it seemed to make no improvement on tool performance in the higher cutting speed such as $125 \mathrm{~m} / \mathrm{min}$. In the present investigation, similar result for lower speed cutting is obtained. But in contrast, it is found that MQL is effective as well even when the cutting speed is as high as $250 \mathrm{~m} / \mathrm{min}$. The reason of this difference may be due to the tool and the oil of MQL used. In their experiment, the inferior heat resistance uncoated carbide tool and the highly viscous oil BP Cilora 128 which has poor cooling ability were used. While in the present study, the coated carbide tool with higher heat resistance and the oil with a better cooling effect such as ES3 were adopted.

In order to identify the influence of lubricant's viscosity on tool life, another lubricant ES1 $\left(28 \mathrm{cSt}\right.$ at $40{ }^{\circ} \mathrm{C}, 0.93 \mathrm{~kg} /$ $\mathrm{m}^{3}$ density) with viscosity similar to BP Cilora 128 , which exhibited a poor cooling effect and a better lubricating effect than ES3 ( $5 \mathrm{cSt}$ at $40^{\circ} \mathrm{C}, 0.86 \mathrm{~kg} / \mathrm{m}^{3}$ density), was adopted as MQL oil in the cutting test. Fig. 5 shows the resulting tool life in terms of cutting length when the MQL oil of ES1 and ES3, respectively, is used. In the experiments, the dispersion of measuring data had been taken into account. For example, the three measurements of cutting length for ES3 under cutting speed of $250 \mathrm{~m} / \mathrm{min}$ 
a

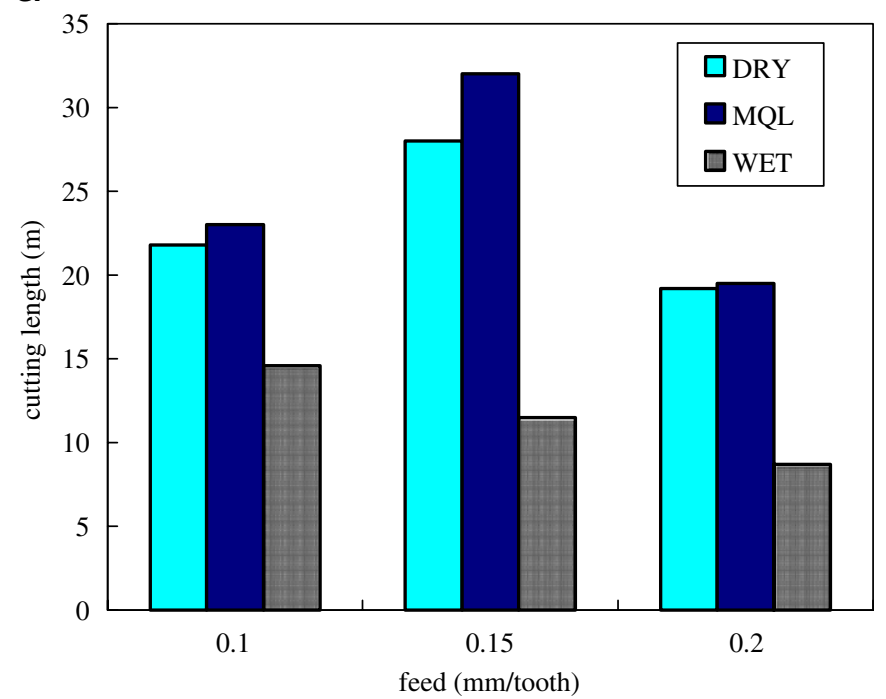

b

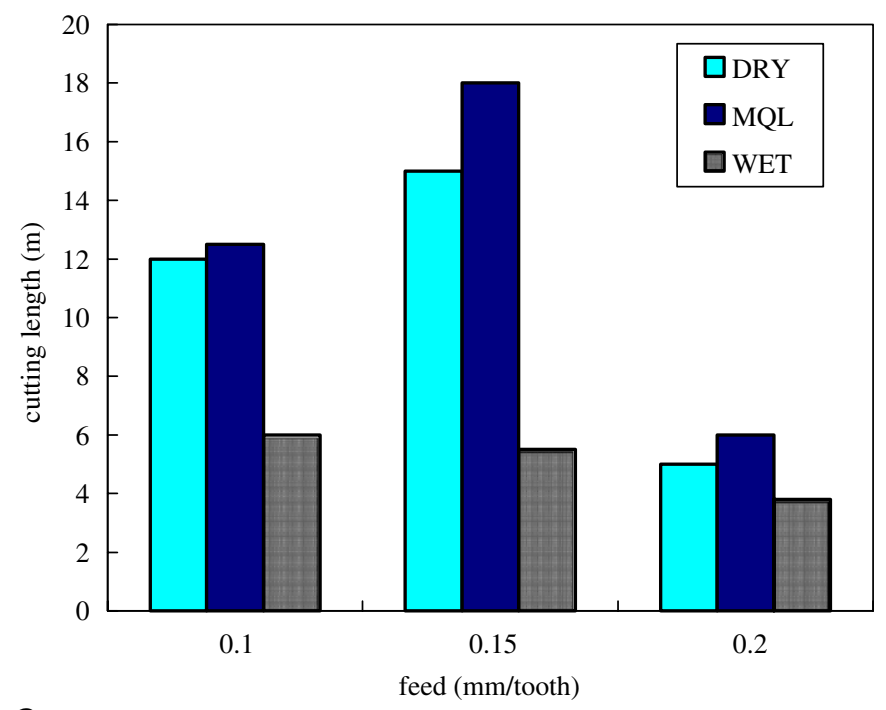

C

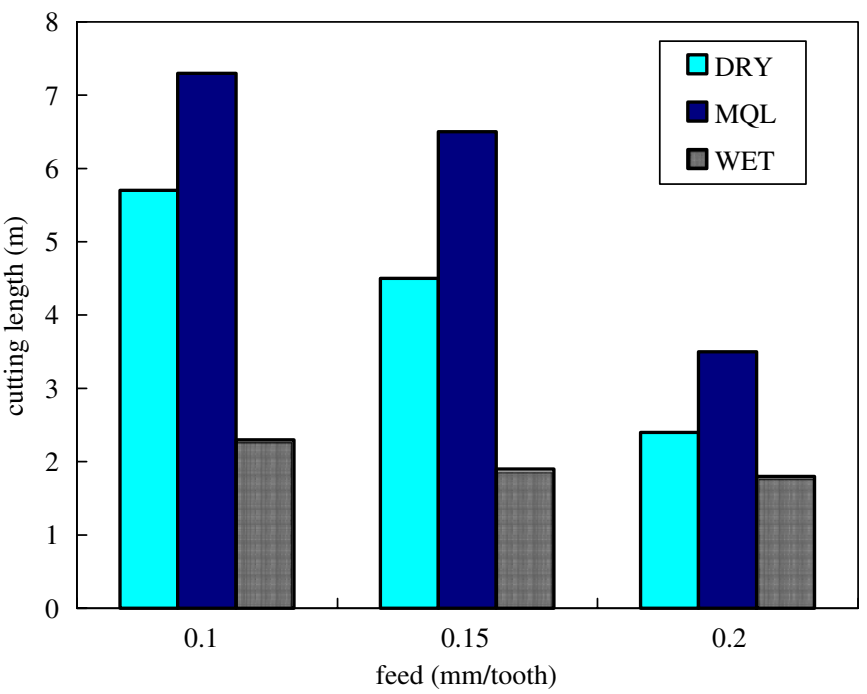

Fig. 2. Tool life as a function of feed rate and lubricating method at various cutting speeds: (a) $V=150 \mathrm{~m} / \mathrm{min}$; (b) $V=200 \mathrm{~m} / \mathrm{min}$; (c) $V=250 \mathrm{~m} / \mathrm{min}$. are $6.7,6.4$, and $6.5 \mathrm{~m}$, respectively. The deviation is within an acceptable range; hence, the average value such as $6.5 \mathrm{~m}$ in this case is taken for representation. Similarly, for ES1, they are 5.9, 5.7, and $5.7 \mathrm{~m}$, respectively, under the same cutting speed condition. The deviation is also very small and the average value of $5.8 \mathrm{~m}$ is taken. It can be seen from the figure, the tool life for ES1 as the MQL oil is longer than that for ES3 in the lower speed cutting such as $150 \mathrm{~m} / \mathrm{min}$. While in the higher cutting speed as $250 \mathrm{~m} / \mathrm{min}$, an opposite trend is observed. The cutting length for ES1 is $34 \mathrm{~m}$ and that for ES3 is $32 \mathrm{~m}$. Percentage wise, it is $6 \%$ longer for high viscous oil than that of low viscous oil in MQL under a lower cutting speed condition ( $V=150 \mathrm{~m} / \mathrm{min})$. But it is $-11 \%$ ( $5.8 \mathrm{~m}$ vs. $6.5 \mathrm{~m})$ shorter under a higher cutting speed condition $(V=250 \mathrm{~m} / \mathrm{min})$. The reason may be due to the fact that low-viscosity oil contains a higher fraction of low molecular weight components, which can volatilize more easily and thereby provides better cooling effect [22]. Based on this result, it is suggested that the oil such as ES1 that exhibited a better lubricating effect is more appropriate as MQL oil in lower speed cutting, whereas the oil with low viscosity is essential in the highspeed cutting.

Fig. 6 shows the associated cutting length under various cutting speeds in dry cutting and MQL cutting, respectively. The percentage increase of tool life for MQL as compared with dry cutting defined as $R_{\mathrm{L}}$ is also given in the figure. It can be readily seen that the improvement of tool life is more significant at higher cutting speeds. Possible reasons of this phenomenon are given as follows. The temperature is very high in high-speed cutting, which leads to very short tool life. Hence, a small increase in tool life would result in a large percentage difference. While in lowspeed cutting, the cutting temperature is not high enough to exceed the limitation that the cutting edge can withstand. Hence, either the lubricating or the cooling effect could give less enhancement of tool life. As a result, the improvement of tool life in the lower speed cutting is not as apparent as that in the higher speed cutting. The influences of cooling effect of MQL on wear mechanism of cutting tool during high-speed cutting are given in next section.

\subsection{Cooling effect of $M Q L$ on the tool wear in high-speed cutting}

Fig. 7(a) shows the photograph of the tool under the toolmaker's microscope after $4 \mathrm{~m}$ cutting length in dry cutting under the condition of $V=250 \mathrm{~m} / \mathrm{min}$ and $\mathrm{fz}=0.15 \mathrm{~mm} /$ tooth; and the tool after $4.5 \mathrm{~m}$ cutting length - when $0.1 \mathrm{~mm}$ maximum flank wear/groove wear has reached, under the same cutting condition, is given in Fig. 7(b). Similarly, Fig. 8(a) represents the tool after $6 \mathrm{~m}$ cutting length in MQL cutting under the condition of $V=250 \mathrm{~m} / \mathrm{min}$ and $\mathrm{fz}=0.15 \mathrm{~mm} /$ tooth; and the tool after $6.5 \mathrm{~m}$ cutting length - when $0.1 \mathrm{~mm}$ maximum flank wear/ groove wear has reached, under the same cutting condition, is presented in Fig. 8(b). It is found that the chips adhered 

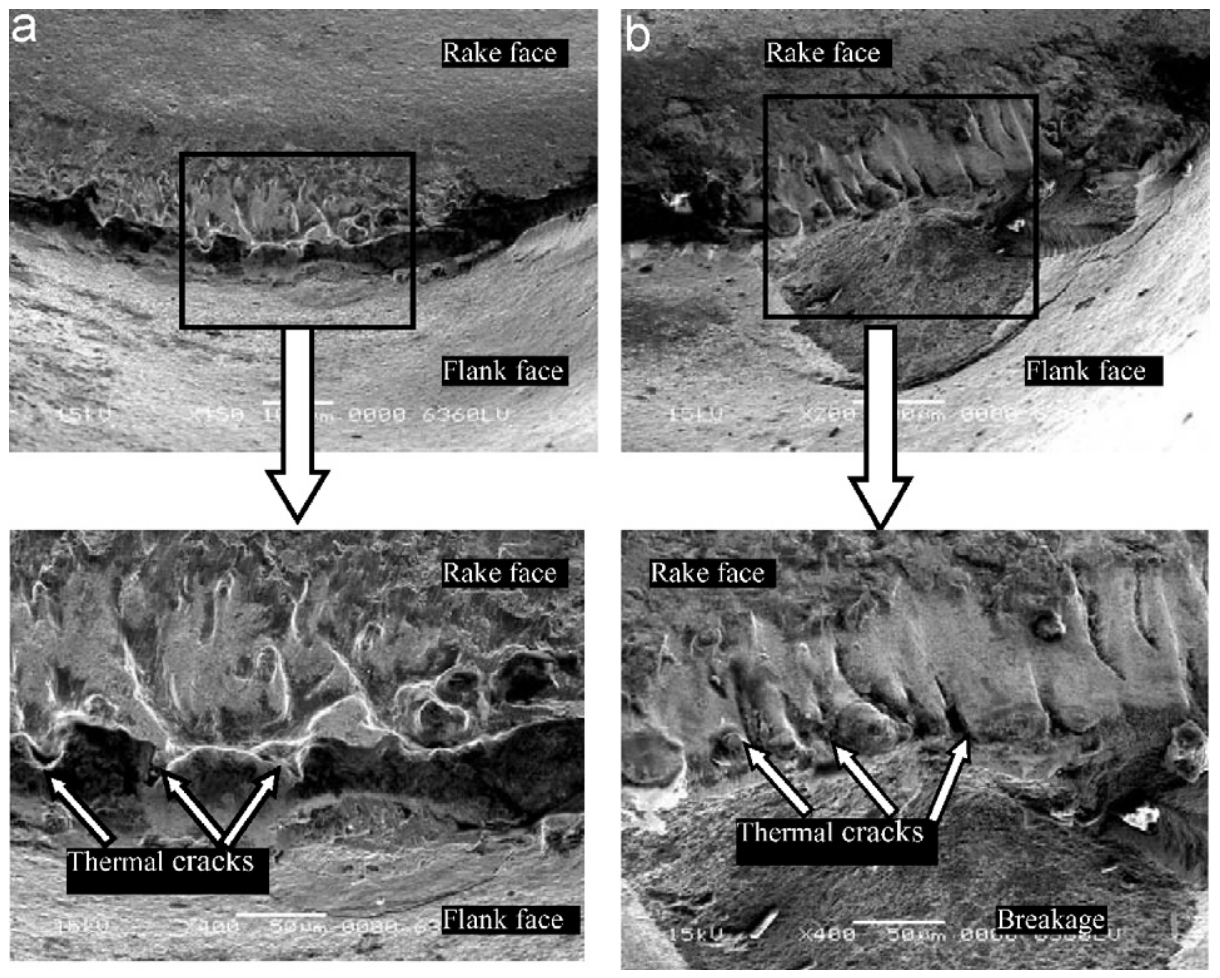

Fig. 3. SEM micrographs of cutting tools observed when the rake face is oriented $-45^{\circ}$ with respect to the cutting edge after (a) $1.8 \mathrm{~m}$ and (b) $1.9 \mathrm{~m}$ cutting length under flood cooling $(V=250 \mathrm{~m} / \mathrm{min}, \mathrm{fz}=0.15 \mathrm{~mm} /$ tooth $)$.
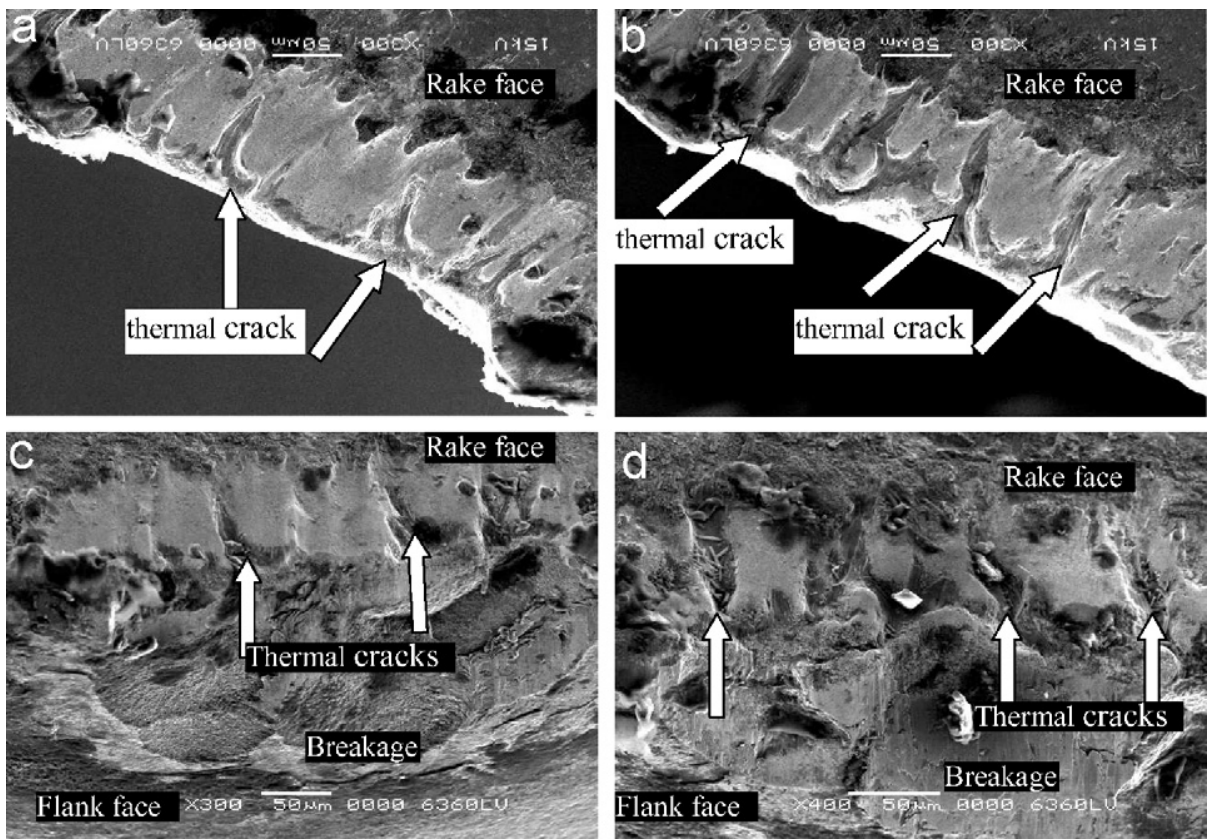

Fig. 4. SEM micrographs of cutting tools under flood cooling when $0.1 \mathrm{~mm}$ maximum flank wear $/$ groove wear has reached: (a) $V=150 \mathrm{~m} / \mathrm{min}$, $\mathrm{fz}=0.15 \mathrm{~mm} /$ tooth, observed from rake face; (b) $V=150 \mathrm{~m} / \mathrm{min}, \mathrm{fz}=0.15 \mathrm{~mm} /$ tooth, observed when the rake face is oriented $-45^{\circ}$ with respect to the cutting edge; (c) $V=200 \mathrm{~m} / \mathrm{min}, \mathrm{fz}=0.15 \mathrm{~mm} /$ tooth, observed from rake face; (d) $V=200 \mathrm{~m} / \mathrm{min}, \mathrm{fz}=0.15 \mathrm{~mm} /$ tooth, observed when the rake face is oriented $-45^{\circ}$ with respect to the cutting edge.

on the rake face (i.e. welding of chips) at the cutting length of $4 \mathrm{~m}$ (marked area in Fig. 7(a)) in dry cutting. As a result, tool wear is accelerated and thereby leads to the more adhesion of chips (referring to Fig. 7(b)) and a short tool life of $4.5 \mathrm{~m}$ cutting length. While in the MQL cutting, welding of chips is absent within $6 \mathrm{~m}$ cutting length (Fig. 8(a)). But eventually, the tool is worn out, and welding of chips would take place. It can be seen from 


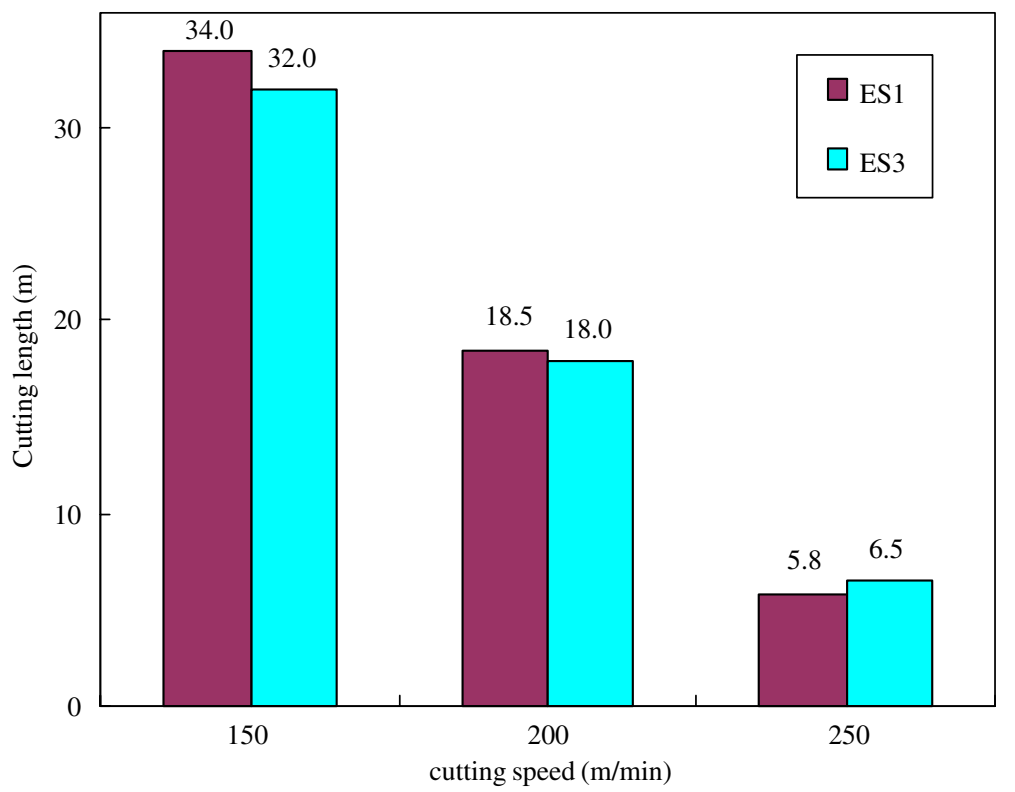

Fig. 5. Comparison of tool life between ES1 and ES3 ( $\mathrm{fz}=0.15 \mathrm{~mm} /$ tooth).

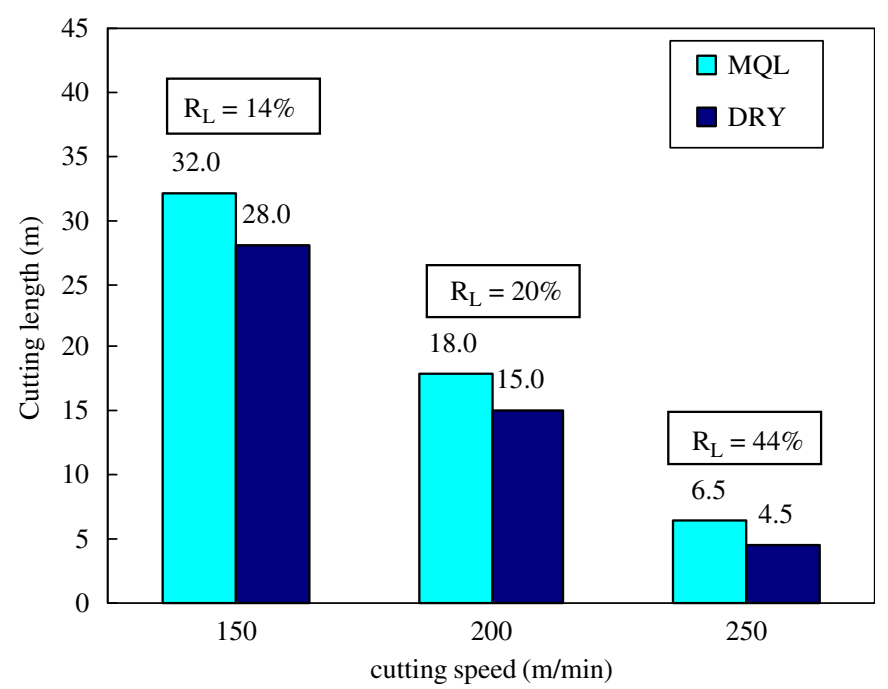

Fig. 6. Tool life elongation ratio $\left(R_{\mathrm{L}}\right)$ for $\mathrm{MQL}$ in comparison with dry cutting ( $\mathrm{fz}=0.15 \mathrm{~mm} /$ tooth).

Fig. 8(b) that there are chips adhered on the rake face at $6.5 \mathrm{~m}$ cutting length. The welding of chips aforementioned occurred in the vicinity of notch (groove) wear. The formation of notch wear is primarily an oxidation phenomenon [23], and it may be due to insufficient wear resistance of insert or too high a cutting speed that results in high cutting temperature. Since a high wear resistance tool is used in this case, it implies that the temperature induced in dry cutting at higher cutting speed, such as $250 \mathrm{~m} / \mathrm{min}$, is high enough to cause notch wear of the cutting tool after a short cutting length. On the contrary, the temperature of the cutting tool seems to reduce effectively with the application of MQL that the occurrence of notch wears and welding of chips are retarded.
The photographs of the insert under the toolmaker's microscope in dry cutting and MQL when $0.1 \mathrm{~mm}$ maximum flank wear/groove wear has reached under the condition of $V=150 \mathrm{~m} / \mathrm{min}, \mathrm{fz}=0.15 \mathrm{~mm} /$ tooth are shown in Fig. 9(a) and (b), respectively. In this case, it is noted that there are no chips adhered on the cutting edge for both dry and MQL cuttings. The wear pattern in dry cutting looks the same as that in MQL cutting. Since cutting temperature is positively related to cutting speed, it is reasonable to believe that the temperature induced in dry cutting at the lower speed cutting, such as $150 \mathrm{~m} / \mathrm{min}$, is not beyond the limitation which the cutting edge can withstand. Hence, the aforementioned improvement of tool life due to MQL at lower cutting speed condition could be the effect other than cooling. Referring to the report of Rahman et al. [20], lubricating effect is an acceptable reason.

In order to make a detailed inspection of the cutting edge in the vicinity of cutting depth, SEM micrographs of insert were taken and EDAX analyses of chips were conducted after $2 \mathrm{~m}$ cutting length. Fig. 10 shows the SEM micrographs of the used inserts. It can be seen from Fig. 10(a) and (b) that under the cutting speed of $150 \mathrm{~m} / \mathrm{min}$, the used tool in dry cutting is similar to that in MQL cutting as given in Fig. 10(c) and (d). There is no adhesion of work material in the vicinity of cutting depth under both cutting conditions. However looking at the dashed lines (the flower-like substances) of the marked area in Fig. 10(f), the welding of chips can be observed in dry cutting under the cutting speed of $250 \mathrm{~m} / \mathrm{min}$. Similar to the previous result, no adhesion is found in MQL cutting as shown in Fig. 10(h).

In the study of Shiao [24], it was found that NAK80 exhibited a tendency to decarburize at high temperature condition. Thus, the carbon content may be regarded as a 

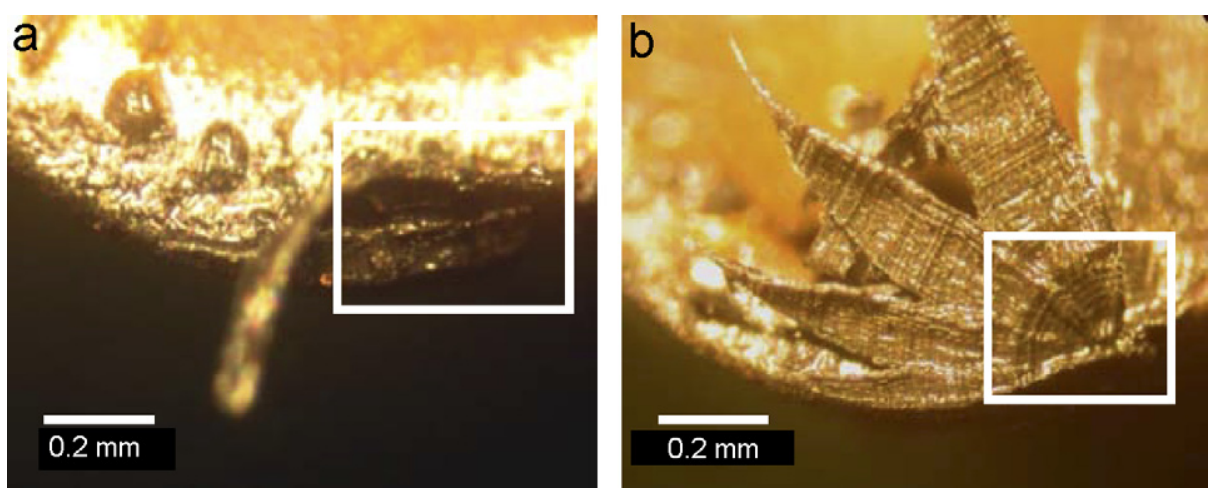

Fig. 7. Photographs of cutting tools under dry cutting (a) after $4 \mathrm{~m}$ cutting length and (b) after $4.5 \mathrm{~m}$ cutting length-when $0.1 \mathrm{~mm}$ maximum flank wear/ groove wear has reached $(V=250 \mathrm{~m} / \mathrm{min}, \mathrm{fz}=0.15 \mathrm{~mm} /$ tooth $)$.
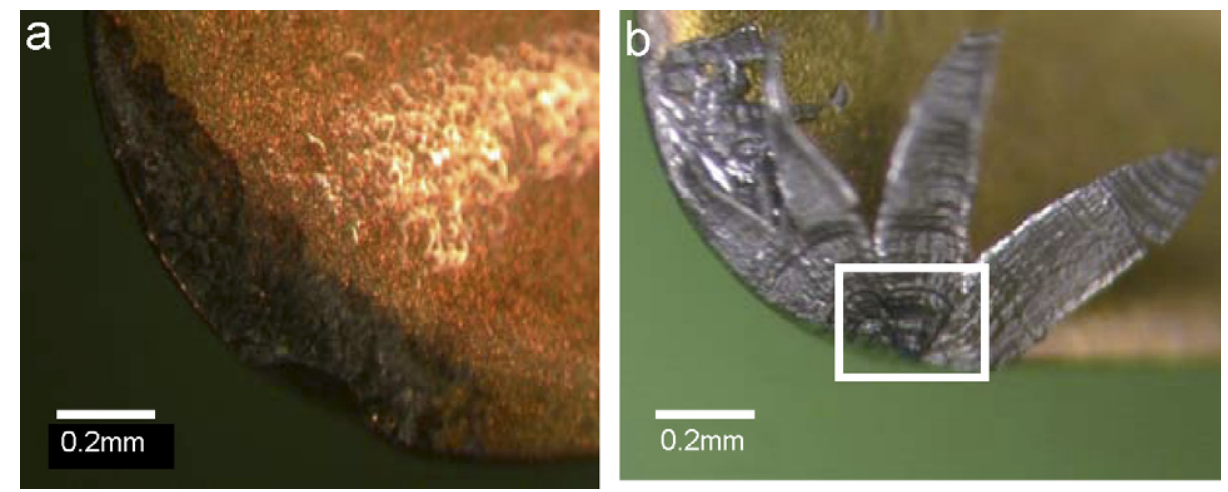

Fig. 8. Photographs of cutting tools for MQL cutting (a) after $6 \mathrm{~m}$ cutting length and (b) after $6.5 \mathrm{~m}$ cutting length —when $0.1 \mathrm{~mm}$ maximum flank wear/ groove wear has reached $(V=250 \mathrm{~m} / \mathrm{min}, \mathrm{fz}=0.15 \mathrm{~mm} /$ tooth $)$.
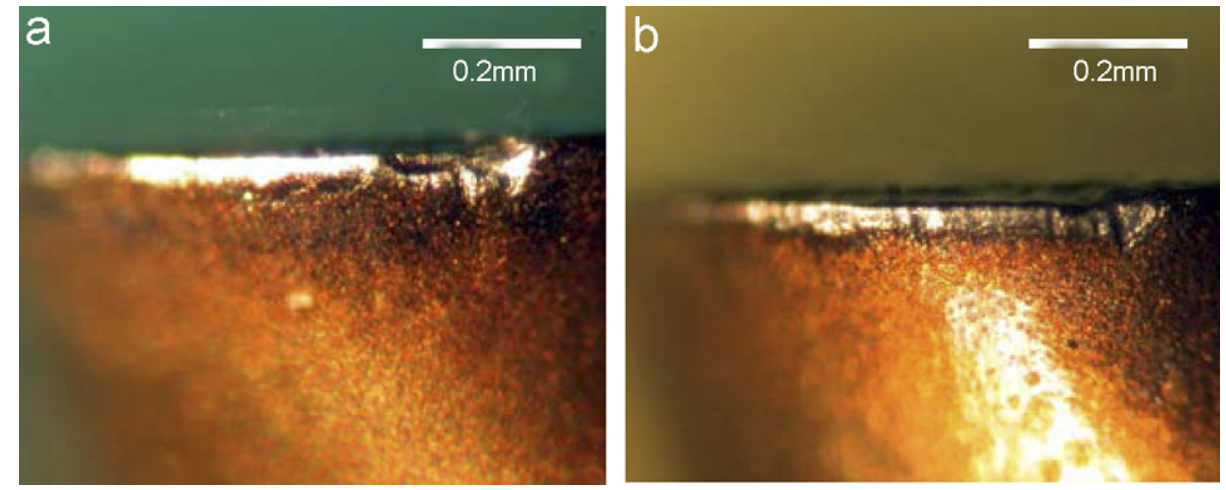

Fig. 9. Photographs of cutting tools when $0.1 \mathrm{~mm}$ maximum flank wear $/$ groove wear has reached: (a) dry cutting and (b) MQL cutting $(V=150 \mathrm{~m} / \mathrm{min}$, $\mathrm{fz}=0.15 \mathrm{~mm} /$ tooth $)$.

result of decarburization due to localized high temperature between the chip-tool interfaces. The EDAX analyses of chips are given in Fig. 11. The decrease of carbon content in MQL cutting as compared with that in dry cutting is more significant at the cutting speed of $250 \mathrm{~m} / \mathrm{min}$ (referring to Fig. 11(c) and (d)) than that at the cutting speed of $150 \mathrm{~m} / \mathrm{min}$ (referring to Fig. 11(a) and (b)). Hence, it is suggested that the use of MQL can reduce cutting temperature effectively in the higher speed cutting so as to improve tool life.

\subsection{Workpiece surface roughness}

Analysis of variance illustrates that feed rate and lubricating method have significant influence on surface roughness as shown in Table 3. Fig. 12 shows the workpiece surface roughness $R_{\mathrm{a}}$ obtained at various cutting speeds. It is shown that the value of surface roughness rises when the feed rate is increased. This result follows general expectation. At a lower cutting speed (such as $150 \mathrm{~m} / \mathrm{min}$ ), the surface roughness in flood 

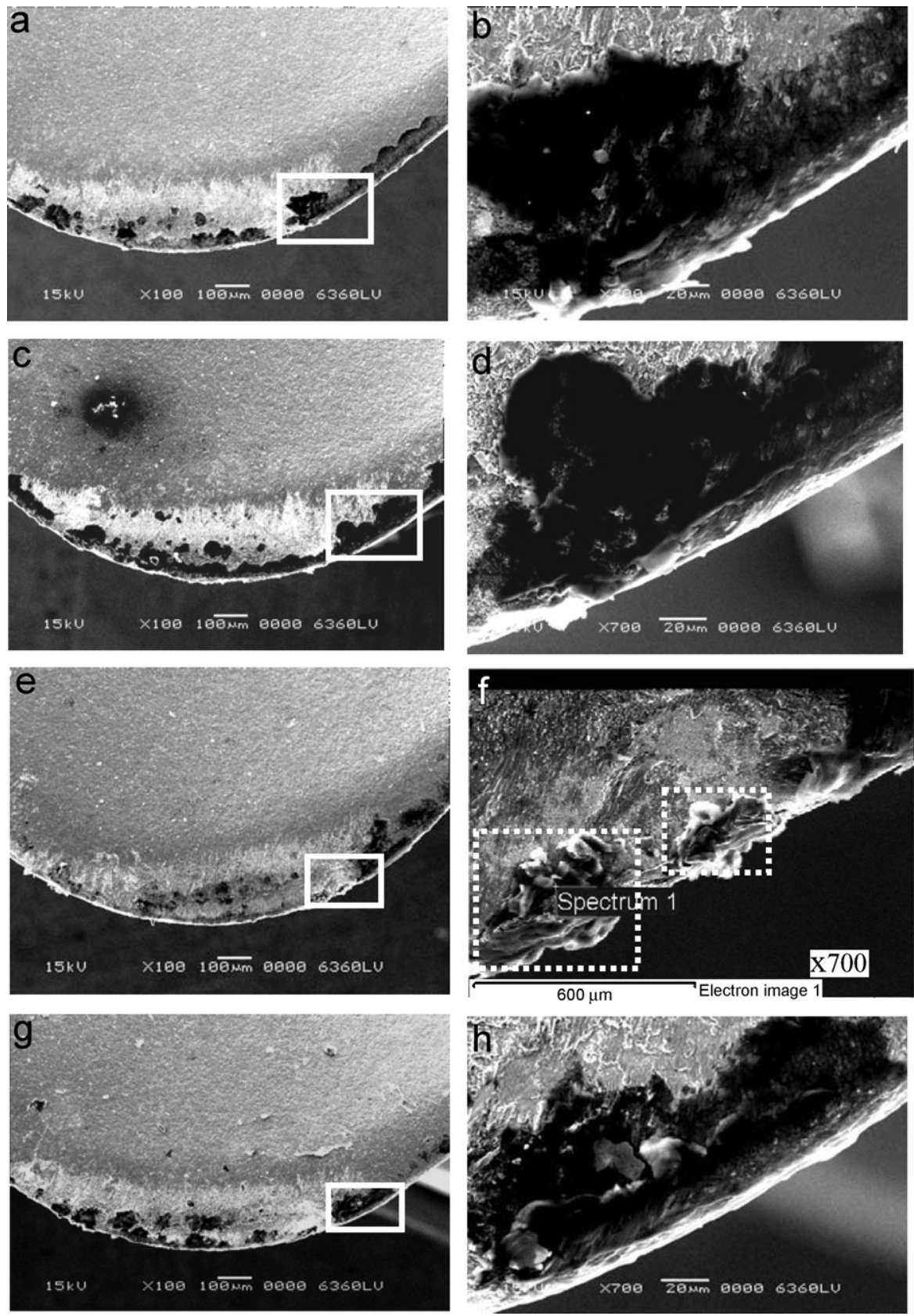

Fig. 10. SEM micrographs of cutting tools after $2 \mathrm{~m}$ cutting length at federate of $0.15 \mathrm{~mm} /$ tooth: (a) $V=150 \mathrm{~m} / \mathrm{min}$, dry cutting; (b) magnification of marked area in Fig. (a); (c) $V=150 \mathrm{~m} / \mathrm{min}$, MQL cutting; (d) magnification of marked area in Fig. (c); (e) $V=250 \mathrm{~m} / \mathrm{min}$, dry cutting; (f) magnification of marked area in Fig. (e); (g) $V=250 \mathrm{~m} / \mathrm{min}$, MQL cutting; (h) magnification of marked area in Fig. (g).

cooling is lower than that in dry and MQL cutting (Fig. 12(a)). As cutting speed is increased, thermal cracks of the cutting tool become more severe (Fig. 4); as a result, a worse surface finish is obtained (Fig. 12(b)). Hence, flood cooling leads to the worst surface finish in higher cutting speed of $V=250 \mathrm{~m} / \mathrm{min}$ (Fig. 12(c)). In contrast, the surface roughness in dry and MQL cutting decreases as cutting speed is increased. It is also noted that in the cutting speed range between 200 and $250 \mathrm{~m} / \mathrm{min}$, the application of MQL results in the best surface finish.

\section{Conclusions}

The feasibility of MQL in high-speed end milling of hardened die steel by coated carbide tool was evaluated and the viscosity of oils for MQL was investigated in this study. It is shown that MQL proved beneficial at highspeed milling when superior heat resistance coated carbide tool and better cooling ability oil are used. The cutting under flood cooling condition results in the shortest tool life due to severe thermal cracks while the use of MQL leads to the best performance for all three cutting speeds. 
In comparison with dry cutting, MQL can delay the formation of welding of chips effectively and hence improve tool life efficiently at a higher cutting speed. A less viscous oil of MQL, containing a higher fraction of low molecular weight components that could volatilize more

a

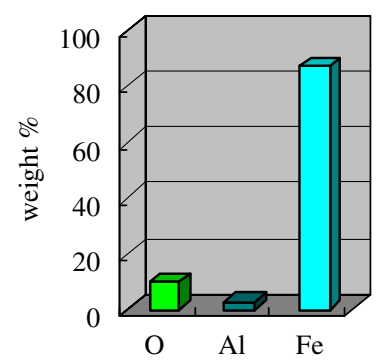

C

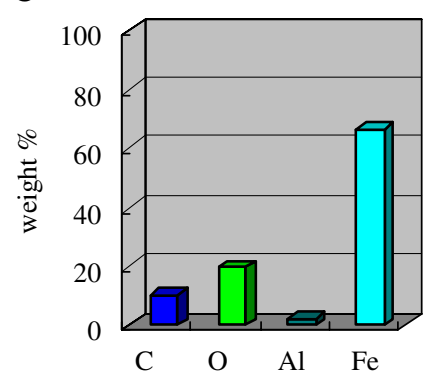

b

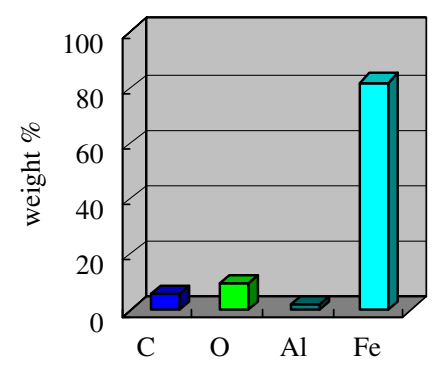

d

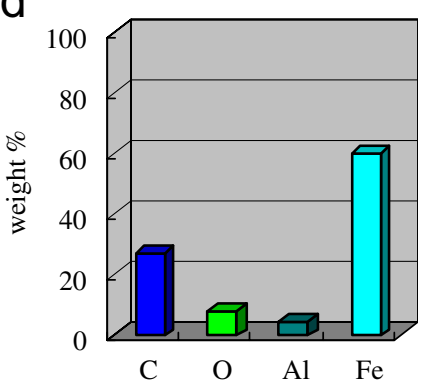

Fig. 11. EDAX analyses of chips after $2 \mathrm{~m}$ cutting length: (a) MQL, $V=150 \mathrm{~m} / \mathrm{min}$; (b) dry cutting, $V=150 \mathrm{~m} / \mathrm{min}$; (c) MQL, $V=250 \mathrm{~m} /$ min; (d) dry cutting, $V=250 \mathrm{~m} / \mathrm{min}$.

Table 3

Analysis of variance (ANOVA) for surface roughness $\left(R_{\mathrm{a}}\right)$

\begin{tabular}{|c|c|c|c|c|c|}
\hline Source & Sum of squares & d.f. & Mean square & $F$ & $P$-value \\
\hline Model & 0.1949 & 6 & 0.0325 & 18.68 & $<0.0001$ significant \\
\hline Feed rate & 0.1568 & 2 & 0.0784 & 45.09 & $<0.0001$ significant \\
\hline Cutting speed & 0.0018 & 2 & 0.0009 & 0.52 & 0.6026 \\
\hline Cutting environment & 0.0363 & 2 & 0.0181 & 10.43 & 0.0008 significant \\
\hline Residual & 0.0348 & 20 & 0.0017 & & \\
\hline Total (corrected) & 0.2297 & 26 & & & \\
\hline
\end{tabular}

a

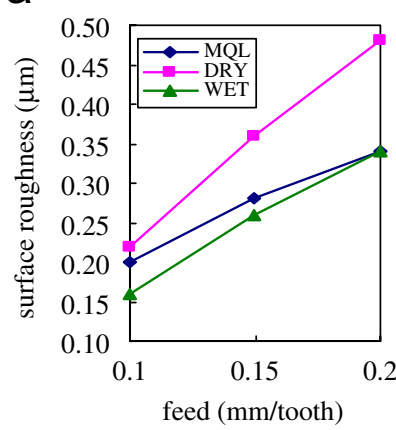

b

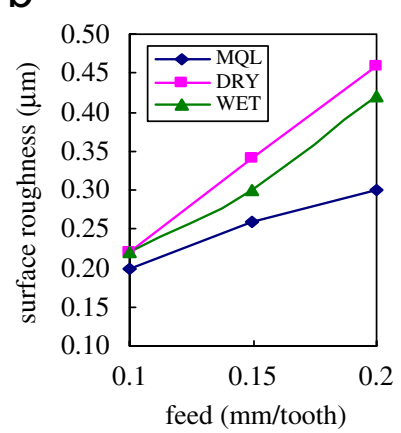

easily is essential in high cutting speed. Finally, the application of MQL also improves machined surface finish in high-speed milling of die steels.

\section{Acknowledgments}

The authors would thank the Industrial Technology Research Institute (ITRI) of Taiwan for their support of the experiments. They are grateful to Castrol Co. Ltd., Taiwan for providing the cutting oil in this study.

\section{References}

[1] P. Koshy, R.C. Dewes, D.K. Aspinwall, High speed end milling of hardened AISI D2 tool steel (58 HRC), Journal of Materials Processing Technology 127 (2002) 266-273.

[2] N. Camuscu, E. Aslan, A comparative study on cutting tool performance in end milling of AISI D3 tool steel, Journal of Materials Processing Technology 170 (1-2) (2005) 121-126.

[3] J.P. Urbanski, P. Koshy, R.C. Dewes, D.K. Aspinwall, High speed machining of molds and dies for net shape manufacture, Materials and Design 21 (2000) 395-402.

[4] H.G. Prengel, P.C. Jindal, K.H. Wendt, A.T. Santhanam, P.L. Hedge, R.M. Penich, A new class of high performance PVD coatings for carbide cutting tools, Surface Coating Technology 139 (2001) 25-34.

[5] F. Klocke, G. Eisenblatter, Dry cutting, Annals of CIRP 46 (2) (1997) 519-526.

[6] M.C. Shaw, Metal Cutting Principles, second ed., Oxford, New York, 2005.

[7] M.A. Elbestawi, L. Chen, C.E. Becze, T.I. EI-Wardany, High speed milling of dies and models in their hardened state, Annals of CIRP 46 (1) (1997) 57-62. 
[8] J.M. Vieira, A.R. Machado, E.O. Ezugwu, Performance of cutting fluids during face milling of steels, Journal of Materials Processing Technology 116 (2001) 244-251.

[9] J.F. Kelly, M.G. Cotterell, Minimal lubrication machining of aluminum alloys, Journal of Materials Processing Technology 120 (1-3) (2002) 327-334.

[10] K. Weinert, I. Inasaki, J.W. Sutherland, T. Wakabayashi, Dry machining and minimum quantity lubrication, Annals of CIRP 53 (2) (2004) 511-537.

[11] H.A. Kishawy, M. Dumitrescu, E.-G. Ng, M.A. Elbestawi, Effect of coolant strategy on tool performance, chip morphology and surface quality during high speed machining of A356 aluminum alloy, International Journal of Machine Tools and Manufacture 45 (2) (2005) 219-227.

[12] F. Itoigawa, T.H.C. Childs, T. Nakamura, W. Belluco, Effects and mechanisms in minimal quantity lubrication machining of an aluminum alloy, Wear 260 (2006) 339-344.

[13] A.S. Varadarajan, P.K. Philip, B. Ramamoorthy, Investigations on hard turning with minimal cutting fluid application (HTMF) and its comparison with dry and wet turning, International Journal of Machine Tools and Manufacture 42 (2) (2002) 193-200.

[14] A.E. Diniz, J.R. Ferreira, F.T. Filho, Influence of refrigeration/ lubrication condition on SAE 52100 hardened steel turning at several cutting speeds, International Journal of Machine Tools and Manufacture 43 (3) (2003) 317-326.

[15] R. Heinemann, S. Hinduja, G. Barrow, G. Petuelli, Effect of MQL on the tool life of small twist drills in deep-hole drilling, International Journal of Machine Tools and Manufacture 46 (1) (2006) $1-6$.
[16] A. Attanasio, M. Gelfi, C. Giardini, C. Remino, Minimal quantity lubrication in turning: effect on tool wear, Wear 260 (3) (2006) 333-338.

[17] C. Bruni, A. Forcellese, F. Gabrielli, M. Simoncini, Effect of the lubrication-cooling technique, insert technology and machine bed material on the workpart surface finish and tool wear in finish turning of AISI 420B, International Journal of Machine Tools and Manufacture 46 (12/13) (2006) 1547-1554.

[18] N.R. Dhar, M. Kamruzzaman, M. Ahmed, Effect of minimum quantity lubrication (MQL) on tool wear and surface roughness in turning AISI-4340 steel, Journal of Materials Processing Technology 172 (2) (2006) 299-304.

[19] J. Sun, Y.S. Wong, M. Rahman, Z.G. Wang, K.S. Neo, C.H. Tan, H Onozuka, Effects of coolant supply methods and cutting conditions on tool life in end milling titanium alloy, Machining Science and Technology 10 (3) (2006) 355-370.

[20] M. Rahman, A. Senthil Kumar, M.U. Salam, Experimental evaluation on the effect of minimal quantities of lubricant in milling, International Journal of Machine Tools and Manufacture 42 (5) (2002) 539-547.

[21] D.A. Axinte, R.C. Dewes, Surface integrity of hot work tool steel after high speed milling experimental data and empirical models, Journal of Materials Processing Technology 127 (2002) 325-335.

[22] B. Bhushan, Principles and Applications of Tribology, Wiley, New York, 1999.

[23] G. Tlusty, Manufacturing Processes and Equipment, Prentice-Hall, New Jersey, 2000.

[24] C.N. Shiao, TEM microstructures of phase transformations and precipitation hardening in copper containing steel, Ph.D. Thesis, Department of Materials Science and Engineering, National Taiwan University, 2000. 